\title{
EVALUATING BLACK WOMEN'S PARTICIPATION, DEVELOPMENT AND SUCCESS IN DOCTORAL STUDIES: A CAPABILITIES PERSPECTIVE
}

\author{
S. Loots* \\ e-mail: lootss@ufs.ac.za \\ L. Ts'ephe* \\ e-mail: lifutso26@gmail.com
}

\author{
M. Walker* \\ e-mail: walkermj@ufs.ac.za
}

${ }^{*}$ Centre for Research on Higher Education and Development (CRHED)

University of the Free State

Bloemfontein, South Africa

\section{ABSTRACT}

Although black women show an increased presence in doctoral study, the probability of intersecting gendered and racial disadvantage is often overlooked through relying on separate numerical transformation progress indicators for gender and race. To take a more active approach to furthering social justice for this marginalised group, we need to explore more holistic ways of mapping transformation. In this sense, we argue for the application of the capabilities approach as an evaluative framework which allows for an assessment of freedoms or capabilities students are able to make use of in pursuing the lives they have reason to value. Furthermore, factors impacting on students' capability formation are also considered, thus providing a multidimensional, ethically individualistic exploration of lives. The experiences of seven black women speak of barriers they have experienced throughout their doctoral journeys, but the data also create a sense of optimism as the potential of capability expansion is addressed.

Keywords: capabilities approach, human development, doctoral, black women, gender, South Africa

\section{INTRODUCTION}

The doctorate degree is viewed by many in knowledge-driven economies as a primary driver for economic development, and in South Africa specifically it acts as an indicator for developmental capacity (Herman 2014). As part of its National Development Plan, the South African Government therefore aims to increase the number of doctoral graduates by 2030 from 
the current graduation rate of fewer than 2000 to 5000 per annum (National Planning Commission 2011, 66). Coupled with the push to increase doctoral output, priority is also given to the rectification of social injustices and inequalities through promoting development and access opportunities for socially marginalised groups such as women, non-white races, and people with disabilities (Department of Higher Education and Training (DHET) 2014b). Unfortunately, the mapping of the transformational progress of these goals is largely limited to numerical representation, with little attention paid to the actual experiences of those in doctoral education, particularly those from marginalised groups. Furthermore, as seen with databases such as those of the United States (US), the data reveal racial and gendered differences as two distinct groupings, thus making it difficult to explore intersectional differences between groups (Johnson-Bailey 2004). More importantly though, it skews data to hide class and power inequalities intersecting with race and gender. From the results of several research studies we know that South African universities are still struggling with gendered and racial climates impacting particularly on the experiences of women and non-white students and staff (e.g. Bhana 2014; Prozesky 2008; Shackleton, Riordan and Simonis 2006; Soudien et al. 2008). However, very few studies have focused particularly on the intersecting impact of gender, race and other social factors, and even less on the context of doctoral education. To bridge these gaps in the promotion of doctoral education, and to render university and doctoral environments more welcoming for marginalised groups, we need more holistic evaluations of lived experiences in these contexts.

This article therefore argues for a human development and capabilities lens for evaluating doctoral students' development, which includes but also extends beyond research skills and knowledge production. This approach focuses on individual well-being and the freedoms or capabilities these individuals have access to in order to reach what they consider to be wellbeing (Sen 1999). Furthermore, the capabilities approach (CA) takes into account personal and structural factors, or conversion factors, which influence individual agency - the ability to make use of capabilities (Crocker and Robeyns 2010). What this evaluation offers is a multidimensional and holistic picture of pathways towards well-being, while specifically bringing to light the freedoms and constraints which could either be expanded on or limited through interventions.

Taking the narratives of seven black ${ }^{1}$ women in doctoral education as the target group for evaluation by means of this approach, the article will first draw attention to numerical progress in doctoral studies. Thereafter we will turn to what more in-depth studies have reported on the impact that gender and race have had on women in doctoral education. We then introduce the 
CA and discuss its potential as an evaluative instrument. The focus will finally turn to identifying the well-being goals, capabilities and conversion factors of the women participating in this research.

\section{GENDER, RACE AND DOCTORAL PARTICIPATION: WHAT THE NUMBERS SAY}

Representation and participation statistics are useful to provide a broad view of numerical equity progress. However, separating gendered and racial representation statistics might skew the data and lead us to believe that women are relatively equally represented in higher education. For example, the Council on Higher Education (CHE) reports that 43 per cent of doctoral enrolments in 2012 were women, as well as 42 per cent of those who graduated in the same year (CHE 2014). However, on closer inspection, racial and gendered differences are still prominent. While black doctoral students in general have a higher enrolment rate (47\%) compared to white students (38\%), less degrees are awarded to black graduates per annum (CHE 2014). In 2012, black women represented 16 per cent of all doctoral enrolments in South Africa, which is a significant increase from the 7.5 per cent who enrolled for doctoral studies in the year 2000 (DHET 2014a). Furthermore, black women's representation in natural science PhDs increased from 3 per cent in 2000 to 8 per cent in 2012 (DHET 2014a). To put these numbers in perspective, however, Table 1 shows the number of racial and gendered groups enrolled for three- or four-year bachelor's, master's and doctoral degrees in 2012 in comparison with the percentage each of these groups represent in the South African population at large. As a social group, black women outnumber all other groups in South Africa (41\%), yet this does not reflect in doctoral participation (South African Institute for Race Relations 2012). Furthermore, compared to the other social groups, black and coloured women are the only groups showing a decreased representation from three- or four-year bachelor's degrees towards doctoral participation, with black women showing a particularly large decline. What this table also reveals is that white women and men still hold considerable advantage in higher and doctoral education representation. Similarly, it seems that men of all races still have the advantage over women with steady increases in numerical representation towards doctoral studies.

When breaking down statistics to highlight the intersections between race and gender, a more realistic representation of participation which also highlights advantage/ disadvantage can be seen. However, statistics fall short in explaining why black women in particular show such slow progress in doctoral participation. We therefore need more in-depth and holistic explorations of these women's experiences in higher and doctoral education in order to further 
participation, transformation and equality beyond numbers.

Table 1: Doctoral enrolments compared for 2012

\begin{tabular}{|l|c|c|c|c|}
\hline & $\begin{array}{c}\text { 3/4 year } \\
\text { B degree }\end{array}$ & Master's & PhD & $\begin{array}{c}\text { \% of SA } \\
\text { population }\end{array}$ \\
\hline Black women & $38 \%$ & $24 \%$ & $16 \%$ & $41 \%$ \\
\hline White women & $13 \%$ & $16 \%$ & $20 \%$ & $5 \%$ \\
\hline Coloured women & $5 \%$ & $3 \%$ & $3 \%$ & $5 \%$ \\
\hline Indian women & $4 \%$ & $4 \%$ & $4 \%$ & $1 \%$ \\
\hline Black men & $25 \%$ & $28 \%$ & $31 \%$ & $39 \%$ \\
\hline White men & $10 \%$ & $16 \%$ & $18 \%$ & $4 \%$ \\
\hline Coloured men & $2 \%$ & $3 \%$ & $3 \%$ & $4 \%$ \\
\hline Indian men & $3 \%$ & $4 \%$ & $4 \%$ & $1 \%$ \\
\hline
\end{tabular}

(DHET 2014a; $2 \%$ of master's and 1\% of PhDs were noted as either unknown gender or race)

\section{EXPERIENCES OF BLACK WOMEN IN DOCTORAL EDUCATION BEYOND NUMERICAL REPRESENTATION}

When considering the data beyond statistics, not many studies have reported on gendered experiences in postgraduate studies and even less explore the intersectional experiences of women in this context. Internationally, Brown and Watson (2010) explored the experiences of eight women in doctoral education in the UK and found that motherhood had a significant impact on doctoral studies. The women in their study reported feeling that domestic demands often outweighed the time allocated to academic life and they found it difficult to move between the roles of mother, wife, student, and in some cases employee. Similar findings from New Zealand report that women undertaking doctoral studies most often seek counselling related to balancing family and time commitments with academia; tension in romantic relationships; negotiating self- and familial perceptions of femininity and gender roles; and dealing with trauma history in relation to their doctoral studies (Carter, Blumenstein and Cook 2013). Balancing academic work, family responsibilities and motherhood often sees women struggling and might contribute to these women dropping out of postgraduate studies (e.g. Ahern and Manathunga 2004; Lynch 2008).

For black women specifically, similar concerns about social expectations have been raised. Johnson-Bailey’s (2004) work on retention and participation issues for female black postgraduate students in the US reveals that women who are mentored and encouraged by university staff and fellow students tend to show greater participation in postgraduate studies. Furthermore, she identifies four issues impacting on the retention of black women in postgraduate studies, which include the presence of and mentoring by supportive professors and staff; the presence of and networking by black peers; respect from the department's 
professoriate; and the availability of continued funding. In reporting on the narratives of 11 postgraduate black women in the US, Robinson $(2013,174)$ finds that the women in her study feel like the minority group in terms of numerical representation, but also regarding feelings of isolation, lack of support and having 'no allies'. These women also experienced an institutionalised culture of racism/sexism irrespective of university mission and vision statements embracing diversity. These barriers motivated them to be successful in their postgraduate studies and to act as role models for other black women. Furthermore, these women stress the importance of acting as an active agent, taking control, standing up for oneself and having a voice.

In South Africa, women have been found to postpone enrolling for doctoral studies due to family responsibilities (Prozesky 2008). For example, they choose to support their husbands in achieving their goals or to wait for their children to grow up and be less dependent on them. Pillay (2009) claims that balancing two lives brings about limitations for academic mothers. This, she states, is a result of the fact that women are traditionally associated with nurturing, love and emotion, while being an academic is traditionally associated with reason and logic. The dual role that women play in comparison with men clearly puts them at a disadvantage.

The limited exploration of black women's doctoral experiences in South Africa also seems to point to a lack of social support from family, the academic community and institutional culture (Magano 2011; 2013; Nkambule 2014). In analysing the experiences of 46 predominantly black women who have either obtained their doctoral degrees or are in the process of obtaining these at a South African institution, Magano (2013) found that having a high workload, trying to balance family, work and studies, as well as trying to enter into maledominated university spaces and institutional cultures as black women, impacted most strongly on these women's academic performance. Although not focused on doctoral studies in particular, Daniels and Damons’ $(2011,165)$ narrative study on coloured women’s experiences in higher education speaks to the broader issues of diversity and inclusion faced by nontraditional students. Being seen as 'the other' impacted on these women's sense of self-worth. The authors report that:

one such negative of being 'othered' was that they are not academically worthy to be at SU [Stellenbosch University]. Their experiences have been that they were being stereotyped as quotas and recipients of tokenism by the majority population on campus as well as by people from their communities.

Although not set out to highlight gendered differences, Portnoi's (2009a; 2009b) research on how new academics are shaped from South African postgraduate student data found that the 
barriers students faced in postgraduate studies include their feeling lost and isolated in their postgraduate studies; having difficulty relating postgraduate experiences to family and friends because of being a first-generation student; having difficult supervisory relationships; insufficient funding for postgraduate studies; feelings of racial inferiority, particularly among black women; experiencing undercurrents of institutionalised racism and culture; and a lack of guidance and support in becoming an academic. Of particular relevance to the current study are Portnoi's findings related to race. The number of black students accessing higher and doctoral education in previously white universities has increased significantly in recent years, which also means that the number of first-generation students has increased accordingly. Herman (2011, 178) argues that black students are generally underrepresented in doctoral studies and have high attrition rates because of the 'chronically dysfunctional school system;' insufficient funding; being first-generation doctoral students with limited role models; moving from academia to industry; and being marginalised by institutional cultures of racism.

There is a clear overlap between national and international literature about the difficulties that women, and particularly black women, experience in higher and doctoral education. The women's voices in these studies testify to feeling isolated, having limited support, and having to deal with unwelcoming institutional cultures. Furthermore, the experiences for these women are intensified in the South African context through the very recent turn from racial oppression to democracy and strong patriarchal values that remain embedded in South African society. We therefore need to ask which freedoms or capabilities these students need in order to reach the valued beings and doings associated with obtaining a doctoral degree, and what keeps them from achieving this goal, particularly for those facing intersecting social inequalities. For this we need a multidimensional evaluative tool such as the CA.

\section{THE CAPABILITIES APPROACH}

The CA (Sen 1992; 1999) is a normative framework intended to measure individual well-being beyond economic indicators towards the freedoms or opportunities (capabilities) people have to actively choose the ways of living they have reason to value (functionings). This approach is holistic in that it considers personal, social and environmental 'conversion factors' that have an impact on the individual's ability to exercise agency in turning capabilities into functionings (Crocker and Robeyns 2010).

Both Sen (1999) and Martha Nussbaum (2000, 2006), who expanded significantly on the approach, see education as a crucial part of human development. As a capability generator, education underpins development through stimulating the formation of reasoning, imagination 
and critical thought. Education is also central to bringing about change and empowerment within individuals as well as in political, social and other contexts (Unterhalter 2009). Regarding higher education specifically, these statements stress the importance of a higher education system that contributes to the personal development of each student by encouraging independent and critical thought, as well as promoting citizenship for the building of a democratic nation (Boni and Walker 2013). Research on the application of the CA in higher education contexts has shown steady growth over the past decade, with particular focus on pedagogies (Walker 2006; Wood and Deprez 2012); transition from school to university (Hart 2013; Walker and Mkwananzi 2015; Wilson-Strydom 2014); doctoral supervision (Walker and Thomson 2010); higher education policy (Walker 2010a); and arguments for a human development and capabilities lens towards a more just higher education system (Boni and Walker 2013; Boni 2014).

Regarding gender and education specifically, Walker (2007) has identified an ideal theoretical capability list for gender equality in schools. The list includes autonomy, knowledge, social relations, respect and recognition, aspiration, voice, bodily integrity and bodily health, as well as emotional integrity and emotions. In higher education, Loots and Walker (2015) identified four core capability themes for gender equality through longitudinal interaction with male and female students. These themes include having a voice; dignity and respect; safety and bodily integrity; and the value of higher education, the latter of which encompasses critical thinking, independence, and citizenship, among other things. The capabilities identified in these studies have the potential to serve as a benchmark for evaluating freedoms associated with gender equality and well-being. They will be revisited later in the article.

The CA, however, is not the only evaluative tool focusing on well-being. In the UK, Juniper, Walsh, Richardson and Morley (2012) developed a measuring instrument to assess doctoral students' subjective sense of well-being. The authors argue that the strong research focus on supervision detracts from a more holistic perspective of factors influencing the wellbeing of doctoral students, and their findings confirm that even though supervision is important, other factors pose a greater threat to their well-being. Along with supervision, their measuring instrument focuses on how development opportunities, physical resources, home and health, the research project, their social support and interactions, and the university environment influence their well-being. Through focusing on a broader conceptualisation of well-being, Juniper and her colleagues suggest that areas of concern might be brought to light, which could prompt interventions to enrich the research experience of doctoral students. Another example of a holistic model for evaluating doctoral well-being is that of Backhouse (2009), who argues 
for an evaluation of the degree of congruence between doctoral students' intersecting contexts to identify where interventions are needed. These intersecting contexts would include family and friends, the workplace, the academic department, the supervisors, and other contexts. While personalised evaluations such as these are certainly a step in the right direction, it has the potential of turning into a problem-solving approach which targets individual problems in the contexts where they arise without considering the intersectional causes or impact of these issues. Furthermore, through only focusing on what problems there are, less attention is given to what works. Probably the most important aspect of the CA which distinguishes it from other holistic evaluative frameworks for doctoral education is the consideration of individual agency, where a person shapes her own destiny by being an active participant in change instead of being a passive and docile recipient of instruction or of dispensed assistance. The combined exercise to expand individual agency through nurturing capabilities and removing or reducing conversion factors impacting negatively on this expansion results in empowerment and freedom to achieve valued functionings (Drydyk 2013). In essence, 'it is the manner in which the capabilities approach foregrounds agency together with the interaction of agents and social contexts that potentially breaks new ground' (Wilson-Strydom 2015, 151). Through shifting the focus to identifying which freedoms should be expanded on to increase the ability of individuals to exercise agency and move towards their valued functionings, the CA takes on a progressive developmental stance as opposed to a problem-solving approach.

\section{METHODS}

This research makes use of a case study approach to 'generate an in-depth, multi-faceted understanding of a complex issue in its real-life context' (Crowe et al. 2011, 1). Case studies seek to engage with and report the complexity of social activity with the intent to represent the meaning that individual social actors make out of their interaction with social environments (Somekh and Lewin 2005). It therefore has the potential to provide a platform for participants to voice their opinions, particularly those from marginalised groups. To represent individual cases, seven black women enrolled for doctoral studies at a previously white South African research and teaching university were selected purposively through emailing those registered for doctoral studies. From the email responses, the seven participants were selected (see Table 2 for a list of participants for whom pseudonyms were given). The women's ages ranged from 27 to 38 and were all in different stages of their doctoral studies. Four of the women were fulltime doctoral students, while two were appointed as lecturers at the University and one was self-employed. All but one of the women's studies were being paid for by bursaries. Four of 
the women were first-generation university students, while all were first-generation doctoral students. Semi-structured interviews focusing on their personal and academic experiences were conducted with the women, after which themes around capabilities, conversion factors, agency and empowerment were extracted through content analysis.

Table 2: Participants

\begin{tabular}{|c|c|c|c|c|c|c|c|}
\hline & Age & $\begin{array}{l}\text { Year of } \\
\text { study }\end{array}$ & Employment & Discipline & Funding & $\begin{array}{l}\text { First } \\
\text { generation } \\
\text { student }\end{array}$ & $\begin{array}{l}\text { Marital and } \\
\text { family } \\
\text { status }\end{array}$ \\
\hline Khanya & 34 & 3 & $\begin{array}{l}\text { Full-time } \\
\text { Private sector }\end{array}$ & $\begin{array}{l}\text { Business } \\
\text { Administration }\end{array}$ & Self & No & $\begin{array}{l}\text { Divorced, } 2 \\
\text { dependants }\end{array}$ \\
\hline Moleboheng & 27 & 2 & $\begin{array}{l}\text { None - } \\
\text { full-time PhD }\end{array}$ & Physics & NRF & Yes & $\begin{array}{l}\text { Single, no } \\
\text { dependants }\end{array}$ \\
\hline Judy & 38 & Submitted & $\begin{array}{l}\text { Full-time } \\
\text { lecturer }\end{array}$ & Education & UFS & Yes & $\begin{array}{l}\text { Single, } 2 \\
\text { dependants }\end{array}$ \\
\hline Palesa & 38 & 3 & $\begin{array}{l}\text { None - } \\
\text { full-time PhD }\end{array}$ & Physics & NRF & Yes & $\begin{array}{l}\text { Divorced, } 3 \\
\text { dependants }\end{array}$ \\
\hline Pinki & 28 & Submitted & $\begin{array}{l}\text { None - } \\
\text { full-time PhD }\end{array}$ & Physics & NRF & Yes & $\begin{array}{l}\text { Single, no } \\
\text { dependants }\end{array}$ \\
\hline Kholu & 34 & 8 & $\begin{array}{l}\text { Full-time } \\
\text { lecturer }\end{array}$ & $\begin{array}{l}\text { Development } \\
\text { studies }\end{array}$ & UFS & No & $\begin{array}{l}\text { Married, } 3 \\
\text { dependants }\end{array}$ \\
\hline Belinda & 32 & 4 & $\begin{array}{l}\text { None - } \\
\text { full-time PhD }\end{array}$ & $\begin{array}{l}\text { Human } \\
\text { Nutrition }\end{array}$ & $\begin{array}{l}\text { Govt of } \\
\text { Ghana }\end{array}$ & No & $\begin{array}{l}\text { Single, no } \\
\text { dependants }\end{array}$ \\
\hline
\end{tabular}

\section{WHAT ARE THE FUNCTIONINGSICAPABILITIES VALUED BY THESE WOMEN?}

Only through identifying what the women have reason to value, i.e. their achieved or aspired functionings, are we able to identify which capabilities contribute to their reaching their desired state of being. We grouped the identified functionings into generic research-related functionings and human development functionings. These will be discussed first, where after we present the capabilities and conversion factors impacting on the women's agency, and therefore their ability to reach these valued functionings.

The women who participated in this study value the development of generic research skills through their doctoral studies, including academic arguing, reading and writing; computer skills; presentation skills; time and financial management skills; and methodological applications. But their valued functionings extend beyond practical research skills to include human development outcomes, such as forming an academic identity and becoming an independent researcher. The capabilities identified through the analysis which are helping them achieve these functionings include developing practical reasoning and critical thinking; gaining confidence and voice; a sense of belonging and recognition; and being treated with respect. Each of these capabilities will be discussed briefly.

\section{Practical reasoning and critical thinking}

All participants stated that, since having undertaken doctoral studies, they have grown to be 
able to be more critical and analytical, not only with regard to their studies, but throughout their lives. The ability to 'form a conception of the good and to engage in critical reflection about the planning of one's life' is termed by Nussbaum $(2000,79)$ as the capability of practical reasoning. The development of critical and analytical thinking as well as self-reflection are known developmental outcomes of doctoral education (e.g. Leonard, Becker and Coate 2005; Magano 2013). As Judy explains:

You know, in my own space, I argued and engaged in a debate with the authors and said I don't agree with Jansen here, for example, as I spoke to Soudien in his absence through his writing, talked with Pillay through her studies. As I spoke to those people, sometimes I would be so upset and really question what they are saying and really question them. That made me grow to an extent, I didn’t even think I would be where I am today, that interrogation, that questioning mood.

\section{Confidence and voice}

The majority of the participants indicated that their doctoral experiences helped them grow confident about their work and about what they are able to do. For example:

Yesterday we had a faculty dialogue where we were discussing issues on critical ways of reasoning and I think I surprised myself, I was talking more than anyone else, maybe because they were discussing matters close to my heart. And for some reason I didn't feel like I did before the $\mathrm{PhD}$, I would feel these are professionals, professors, these are men, because most of them are men, white people, where do I start. I didn't even think of that, for me they were colleagues, but when I first started working here they were superior, now they are colleagues because I can talk and discuss issues. (Judy)

There were also instances where the women's voices felt restricted, or as Pinki states below, being in a predominantly male discipline she feels that women's voices are still not valued as much as men's contributions:

I find it very challenging because even when you want to initiate something, it's not going to take off just like that as compared to when males suggested it ... It takes more courage to be in a maledominated environment.

The confidence these women speak about is strongly associated with developing an academic identity, but also adds to recognition of self-worth, as Judy says:

I feel like the PhD helps you to negotiate your identity between being black, a woman, and being an academic, because sometimes we come with our own biographies which are characterised by ideologies of weaknesses and say I know I am black and weaker and they are stronger. I am black I can't make it and they can. You come up with a pre-written biography which you impose on yourself and other people around you impose on you, and as you work through, you grow, and 
you end up re-writing the biography where you say 'I know I can'.

\section{Sense of belonging and recognition}

The participants claim that exposure to presenting at conferences both locally and internationally helped build their freedom to create an academic identity. This exposure overlaps with gaining confidence and voice as well as creating a sense of belonging to the academic world and contributes to their becoming independent researchers. As Pinki says:

It has improved my communication skills, because I went to a lot of conferences and that has boosted my confidence and presentation skills.

Related to developing a sense of belonging is professional recognition from those who matter to us. Professional recognition is explained by Judy as:

For me it is a sense of pride and a sense of feeling I belong, when you don't have a Dr on your door, you feel like you don't belong, like you are not part of the institution. It's about who am I, how do I address myself, how do my colleagues address me, how do my students address me, so you understand it's all about a sense of pride, it's all about feeling welcome in this place, feeling like you belong and feeling like you can add value to this space.

The capability for recognition extends beyond the professional environment for these women. The women also placed value on having role models and being role models for other women. As Kholu says:

I remember one time when I was attending a graduation ceremony and I was wearing my gown and the young girls were impressed and asked me what the red gown symbolises and I explained that it is a doctor's gown and they could ask because I think they thought I was approachable. At least for the young ladies around me they will have something to look up to.

\section{Being treated with respect}

The women in this study placed value on being respected and recognised beyond racial and gendered stereotypes. For example, as Palesa states:

When you are a woman, many people consider you subordinate to your male counterpart, and during this democratic era people say opportunities are more for women and I honestly don't see that, rather I say we as women are more vulnerable, and you know how a vulnerable person is, our nature as women makes us vulnerable, for the mere fact that when I get there and people see a woman makes me less of a person, people just see that I belong in the home taking care of the husband, that's what comes to mind to people before they even know what I am capable of doing as a person. 
Similarly, Judy shares her experiences of feeling marginalised because of her race:

They [colleagues in the department] look at you through the glasses of race and immediately they feel you are inadequate, immediately when they look at you through those glasses they feel you cannot make it because of your skin colour, I can't say of being female, but it was mostly of colour, race.

\section{WHICH CONVERSION FACTORS INFLUENCE AGENCY?}

Conversion factors are those personal, social and environmental factors impacting on individual agency - in other words, to make use of, and develop capabilities towards the life one values (Crocker and Robeyns 2010). For the women participating in this study, societal roles, expectations and balancing acts; institutionalised racism/sexism; loneliness and isolation; funding and equity interventions; and life events were central factors impacting on their agency. These will be discussed briefly.

\section{Societal roles, expectations and balancing acts}

Like the majority of literature on women in doctoral education, the participants sometimes felt overwhelmed with balancing social expectations placed on them (often by themselves too), motherhood, and academics. For example:

Us as Africans, our duty as women is to take care of the family. My husband helps out with chores in the house, but as a woman I cannot always expect him to do everything and even if he did, you know how men do it, they are not as conscious as us women (Kholu).

I am a mother of four children and they are far from me, and sometimes they really need me. If my children need my time, I just go, I don't care what point or stage I am at with my work, I just pack and leave. A mother should always be there for growing kids, a mother should always be there (Palesa).

In contrast to these and other findings in literature, Johnson-Bailey (2004) reports that the women in her study never mentioned childcare and family obligations. However, when asked about it, they did comment on societal pressure and expectations regarding these personal relationships and their roles as mothers and wives; factors which influenced their retention.

\section{Institutional racism/sexism}

Most of the participants indicated that being a woman within their disciplines made them vulnerable to discrimination. This was particularly stressed by those in physics, which is primarily a male-dominated discipline. For example, Moleboheng's statement below shows 
how the women in the Physics department feel subjected to stereotypes:

This is one of the departments people keep on saying it's not for women, and if you are a woman in this department you won’t be able to make it, you will only be here for a short while.

For others, the racial climate had a more negative impact on their studies, as Kholu states: 'I don't find problems with regards to being a woman, but more on being black'. These inequalities are perpetuated by a lack of an enabling environment, which hinders women's progress and maintains cultural barriers (Magano 2013). The two women who are employed as lecturers at the university were more sensitive to the unequal institutional culture regarding race and gender.

\section{Loneliness and isolation}

All participants commented on the loneliness and isolation associated with doctoral studies, for example, as Judy says:

Somehow you have this topic that you have thought about and you are the only person who has a passion for this ... So the literature searches, trying to understand this topic, trying to frame the topic in the words that are acceptable, it is your own burden. It is your own battle.

This finding corresponds to broader literature on the isolating nature of doctoral studies, and for women in particular because of gender role demands (e.g. Brown and Watson 2010). However, the loneliness and isolation experienced by this group of women extends beyond the norm. As with other findings on black women, the women in our study also report experiencing loneliness and isolation because of a lack of similar people to identify with (Johnson-Bailey 2004; Magano 2011; 2013; Nkambule 2014; Robinson 2013). Although the university where the participants are undertaking their doctoral studies has a female teaching and research staff of 48 per cent, and a black staff ratio of 21 per cent (DHET 2013), it difficult to say how many of the 21 per cent black academic staff are black women. Furthermore, being a first-generation (doctoral) student has impacted on the support these women receive from family and friends. As Kholu and Moleboheng state:

[My husband has] matric. That's one of the reasons why he doesn't understand. It's not like he intentionally doesn't want to support, it's just that he has not been to tertiary or any higher education institution. (Kholu)

At home it is a bit difficult to communicate with other people to say this is what I'm doing, and this is how I want to do it. It's difficult because they still don't understand, it's like 'since we've 
known you you've been studying, are you ever going to finish?' (Moleboheng)

Academic social support from supervisors, peers and other academics also impacted on the women’s agency, confidence and self-assurance. For example, Belinda and Pinki say:

We used to have seminars presentations, and these were for sharing one's work with the group, it's not like a group discussing issues, it's about presenting. You don't have classes to attend, you don't have forums where you can meet as postgraduate students, but then we have seminars and colloquiums for the faculty which happen once a year. (Belinda)

My supervisor gave me the freedom of saying, choose a project for yourself, tell me what you want to do, give me the advantages and disadvantages, and tell me how you think we can turn the disadvantages into advantages. And by doing so, [he] taught me to be upfront and be dependent on myself, and trust in myself as well. (Pinki)

The development of students by expanding their opportunities or capabilities through the supervision process not only creates the knowledge that workers need to strengthen the knowledge economy, but also aids in shaping empowered citizens who are able to engage critically with the production of relevant and reflective knowledge (Walker 2010b). In contrast, the lack of a supportive supervisor could impact dramatically on the student's progress and success.

\section{Funding and equity opportunities for women}

Most participants, especially those with children, identified funding as a major source of their anxiety and negatively affected their studies. Funding initiatives, particularly targeting marginalised groups to increase doctoral participation, played a role in getting most of the participants into doctoral education, as in Pinki's case: 'When it comes to funding they go for black women, so that's also what kept me going'. However, the funding is often not enough to support themselves and a family, as in the case of Palesa, whose children live with family because she cannot afford to keep them with her. Magano (2011) has also stressed that financial support through bursaries is not enough to promote equity and that emotional and social support from both the academic community as well as family and friends are necessary.

\section{Life events}

Several life-changing events impacted on their doctoral education. During their pursuit of doctoral studies, these women experienced deaths in family; marriage and starting families; personal health issues, including one participant finding out she is HIV positive; supervisor illness; and getting divorced. Even though these life events acted as significant stressors to the 
participants and for some it influenced their progress, all of the women showed great resilience and determination to continue with their doctoral studies.

\section{DISCUSSION}

The women in this study were in agreement over the aspired functionings they wish to achieve from their doctoral studies. Beyond the generic research skills, they all commented on wanting to develop into academics, in other words, to take on the identity of an academic who is respected by students and peers, who can contribute to knowledge production, and who belongs to a certain community.

Although contextually different, the capabilities overlap significantly with those identified by Walker (2006) and Loots and Walker (2015) in the South African school and higher education contexts respectively. The only two capabilities which featured in both the abovementioned 2015 and 2006 studies and were not explicitly mentioned by the current participants are capabilities for bodily integrity, safety and bodily health; and independence/autonomy. However, contextually, the women in this study are older, and thus might have already achieved a sense of autonomy. Moreover, being vulnerable to issues impacting on bodily integrity, such as sexual harassment, seems to be less pertinent in the doctoral context compared to undergraduate students living on campus (Loots and Walker 2016) and within schools (Walker 2006). This does not imply that such behaviours are absent, but merely that they were not mentioned by the participants. Expanding on the capabilities identified by the participants in this study brought them closer to achieving their valued ways of being. However, access to developing these capabilities is not always straightforward. Conversion factors, such as the ones mentioned above, impact on individual agency, and therefore the ability to develop and make use of capabilities. It is easy to see how the conversion factors impacting positively on agency and capability expansion for these women have aided their development through their doctoral studies, for example, Pinki and Belinda's statements on receiving academic support and exposure to developmental opportunities. Opportunities for funding also impacted on many of the participants' choice to continue with their doctoral studies. However, the impact of conversion factors constricting agency was also evident. For example, one could assume that an unwelcome gendered and racial environment has at least some influence on the lack of participation in doctoral studies for black women. However, for this group, even though they feel marginalised because of negative gender and/or racial environments, particularly in the male-dominated fields of study, this enhanced their sense of determination to succeed. Similar findings of negative experiences increasing determination for black women have been found. 
For example, Nkambule $(2014,2007)$ states that 'it is eventually how you respond to the challenges, by not allowing racial and belittling stereotypes to have a negative effect on you, but using them to gain strength and to triumph to achieve your own goals'. Even though the institutional racial and/or gendered climate has the potential to increase determination and resilience, it constricts agency freedom in that the marginalisation keeps them from developing capabilities for belonging and recognition, respect, confidence and voice. Furthermore, the lack of social support, insufficient funding, social roles and expectations, and general life events all have similar effects on their agency freedom. Each individual's conversion factors impacting on their agency will differ. Exploring the weight placed on conversion factors by doctoral students, and in particular marginalised groups, is therefore important to increase retention and participation.

What institutions can do with evaluations such as these is to increase public dialogues on socio-cultural and institutionalised norms regarding gender and race. Sen (1999) regards public discussion as a vehicle for social change and argues for democratic deliberations and critical scrutiny to address issues such as inequalities conveyed through social and institutional norms. This is supported by Daniels and Damons (2011), who recommend encouragement of open dialogue between students and institutions. Furthermore, this study's findings concur with Herman's (2011) suggestion that doctoral pedagogies and programmes have to adapt to the increased diversity of its students beyond merely providing funding. This could also include setting up and promoting peer discussion groups and counselling.

Because students are individuals with their own reasons for pursuing doctoral education, we cannot generalise that the same functionings are valued by all doctoral students. However, with further research, the overlap of capabilities could provide holistic transformative indicators which we as supervisors and institutions should expand to increase students' agency towards completion and beyond.

\section{CONCLUSION}

This article aimed to introduce the capabilities approach as a valuable evaluative tool, particularly for marginalised students such as black women undertaking doctoral studies. In the pursuit of transformation in universities, it is crucial to scrutinise whether supportive and enabling environments have been created for those who have been marginalised. There is thus a need for continued documentation of black women's experiences in academia due to the impact of socio-cultural and structural domination and marginalisation (Maodzwa-Taruvinga and Divala 2014). For these women, higher education environments are often ignorant of the 
gendered and racial difficulties they face which impact on their sense of belonging and academic identity formulation (Divala 2014). It is thus vital to keep the momentum of this conversation in pursuit of both the proposed social justice outcomes as well as the knowledgeproduction outcomes of higher and doctoral education in South Africa.

Using a multidimensional framework such as the CA, we are able to compare students' capability needs. It further enables us to see where advantage is being produced, how and for whom, and who is being disadvantaged as an ethical concern. Thus, the CA introduces an ethical dimension to work on doctoral education, as well as the broader human development dimension which asks 'doctoral education for whom and why?' This is important because, ultimately, the knowledge economy depends on what happens to the knowledge created through doctoral education, not simply the number of doctoral graduates produced. Furthermore, in order for doctoral graduates to effectively and critically navigate the sustainable creation of quality knowledge, opportunities for the development of these skills and insight must be provided.

\section{NOTE}

1. The racial classification of 'black' includes all non-white racial groups classified and disadvantaged by the apartheid government, however, the focus of this article is on African women specifically.

\section{REFERENCES}

Ahern, K. and C. Manathunga. 2004. Clutch-starting stalled research students. Higher Education 28(4): 237-254.

Backhouse, J. P. 2009. Doctoral education in South Africa: Models, pedagogy and student experiences. $\mathrm{PhD}$ thesis, University of the Witwatersrand, South Africa.

Bhana, D. 2014. Race matters and the emergence of class: Views from selected South African university students. South African Journal of Higher Education 28(2): 355-367.

Boni, A. 2014. Professional education, capabilities and the public good: The role of universities in promoting human development. Journal of Human Development and Capabilities 15(2-3): 291292.

Boni, A. and M. Walker, ed. 2013. Human development and capabilities: Re-imagining the university of the twenty-first century. Oxon: Routledge.

Carter, S., M. Blumenstein and C. Cook. 2013. Different for women? The challenges of doctoral studies. Teaching in Higher Education 18(4): 339-351.

CHE see Council on Higher Education.

Council on Higher Education. 2014. Vital stats 2012. Pretoria: Council on Higher Education.

Crocker, D. A. and I. Robeyns. 2010. Capability and agency. In Amartya Sen, ed. C. Morris, 60-90. Cambridge: Cambridge University Press.

Crowe, S., K. Cresswell, A. Robertson, G. Huby, A. Avery and A. Sheikh. 2011. The Case Study Approach. Medical Research Methodology 11(100): 1-9.

Daniels, D. and L. Damons. 2011. 'I am more than just a coloured woman': Narrating undergraduate 
experiences at a historically white South African University. Africa Education Review 8(1): 148168.

Department of Higher Education and Training. 2013. Statistics on post-school education and training in South Africa 2011. http://www.dhet.gov.za/DHET\%20Statistics\%20Publication/Statistics\% 20on\%20Post-School\%20Education\%20and\%20Training\%20in\%20South\%20Africa\% 202012.pdf (accessed 10 January 2015).

Department of Higher Education and Training. 2014a. Higher education management and information system. Republic of South Africa. http://www.dhet.gov.za/SitePages/Org_Universities.aspx (accessed 4 November 2014).

Department of Higher Education and Training (DHET). 2014b. White Paper for post-school education and training: Building an expanded, effective and integrated post-school system. Pretoria: DHET.

DHET see Department of Higher Education and Training

Divala, J. J. 2014. Editorial. Part 2: Being and belonging in South African higher education: The voices of black women academics. South African Journal of Higher Education 28(6): 1959-1960.

Drydyk, J. 2013. Empowerment, agency, and power. Journal of Global Ethics 9(3): 249-262.

Hart, C. 2013. Aspirations, education and social justice: Applying Sen and Bourdieu. London: Bloomsbury.

Herman, C. 2011. Elusive equity in doctoral education in South Africa. Journal of Education and Work 24(1-2): 163-184.

Herman, C. 2014. The South African doctorate. In Pushing boundaries in postgraduate supervision, ed. E. Bitzer, R. Albertyn, L. Frick, B. Grant and F. Kelly, 39-53. Stellenbosch: Sun Press.

Johnson-Bailey, J. 2004. Hitting and climbing the proverbial wall: Participation and retention issues for black graduate women. Race Ethnicity and Education 7(4): 331-349.

Juniper, B., E. Walsh, A. Richardson and B. Morley. 2012. A new approach to evaluating the well-being of PhD research students. Assessment \& Evaluation in Higher Education 37(5): 563-576.

Leonard, D., R. Becker and K. Coate. 2005. To prove myself at the highest level: The benefits of doctoral study. Higher Education Research \& Development 24(2): 135-149.

Loots, S. and M. Walker. 2015. Shaping a gender equality policy in higher education: Which human capabilities matter? Gender and Education 27(4): 361-375.

Loots, S. and M. Walker. 2016. A capabilities-based gender equality policy for higher education: Conceptual and methodological considerations. Journal of Human Development and Capabilities 17(2): 260-277.

Lynch, K. D. 2008. Gender roles and the American Academe: A case study of graduate student mothers. Gender and Education 20(6): 585-605.

Magano, M. 2011. The social and emotional challenges of female postgraduate students in South Africa. Journal of Social Science 29(3): 205-212.

Magano, M. 2013. The lament of a female postgraduate PhD Student at a South African university: An academic wellness perspective. International Journal of Higher Education 2(2): 211-221.

Maodzwa-Taruvinga, M. and J. J. Divala. 2014. Experiences of black women teacher educators in the South African higher education system. South African Journal of Higher Education 28(6): 19611971.

National Planning Commission of South Africa. 2011. National Development Plan. http://www.npconline.co.za/pebble.asp?relid=25 (accessed 11 June 2013).

Nkambule, T. 2014. Against all odds: The role of 'community cultural wealth' in overcoming challenges as a black African woman. South African Journal of Higher Education 28(6): 1999-2012.

Nussbaum, M. 2000. Women and human development. Cambridge: Cambridge University Press.

Nussbaum, M. 2006. Education and democratic citizenship: Capabilities and quality education. Journal 
of Human Development 7(3): 385-396.

Pillay, V. 2009. Academic mothers finding rhyme and reason. Gender and Education 21(5): 501-515.

Portnoi, L. 2009a. Cultivating the next generation of academics in South Africa. Africa Education Review 6: 182-207.

Portnoi, L. 2009b. To be or not to be an academic: South African graduate students' vocational choices. International Journal of Educational Development 29: 406-414.

Prozesky, H. 2008. A career-history analysis of gender differences in publication productivity among South African academics. Science Studies 21(2): 47-67.

Robinson, S. J. 2013. Spoketokenism: Black women talking back about graduate school experiences. Race Ethnicity and Education 16(2): 155-181.

Shackleton, L., S. Riordan and D. Simonis. 2006. Gender and the transformation agenda in South African higher education. Women's Studies International Forum 29: 572-580.

Sen, A. 1992. Inequality re-examined. Oxford: Oxford University Press.

Sen, A. 1999. Development as freedom. New York: Alfred A. Knopf.

Somekh, B. and C. Lewin. 2005. Research methods in the social sciences. London: Sage Publications.

Soudien, C., W. Michaels, S. Mthembi-Mahanyele, M. Nkomo, G. Nyanda, N. Nyoka, S. Seepe, O. Shisana and C. Villa-Vicencio. 2008. Report of the Ministerial Committee on Transformation and Social Cohesion and the Elimination of Discrimination in Public Higher Education Institutions. Pretoria: Department of Education.

South African Institute for Race Relations. 2012. South African survey: Demographics. Pretoria: SAIRR and Unit for Risk Analysis.

Unterhalter, E. 2009. Education. In An introduction to the human development and capability approach: Freedom and agency, ed. S. Deneulin and L. Shahani, 207-227. London and Washington, DC: Earthscan.

Walker, M. 2006. Higher education pedagogies. Maidenhead: Society for Research into Higher Education and Open University Press.

Walker, M. 2007. Selecting capabilities for gender equality in education. In Amartya Sen's capability approach and social justice in education, ed. M. Walker and E. Unterhalter, 178-195. London: Palgrave.

Walker, M. 2010a. A human development and capabilities 'Prospective analysis' of global higher education policy. Journal of Education Policy 25(4): 485-501.

Walker, M. 2010b. Doctoral education as 'capability' formation. In The Routledge Doctoral Supervisor's Companion: Supporting effective research in education and the social sciences, ed. M. Walker and P. Thomson, 29-37. Abingdon: Routledge.

Walker, M. and P. Thomson, eds. 2010. The Routledge Doctoral Supervisor's Companion: Supporting effective research in education and the social sciences. Abingdon: Routledge.

Walker, M., and F. Mkwananzi. 2015. Theorising multiply disadvantaged young people's challenges in accessing higher education. Perspectives in Education 33(1): 12-25.

Wilson-Strydom, M. 2014. A capabilities list for equitable transitions to university: A top-down and bottom-up approach. Journal of Human Development and Capabilities DOI: 10.1080/19452829.2014.991280.

Wilson-Strydom, M. 2015. University access and theories of social justice: Contributions of the capabilities approach. Higher Education 69: 143-155.

Wood, D., and L. S. Deprez. 2012. Teaching for human well-being: Curricular implications for the capability approach. Journal of Human Development and Capabilities 13(3): 471-493. 